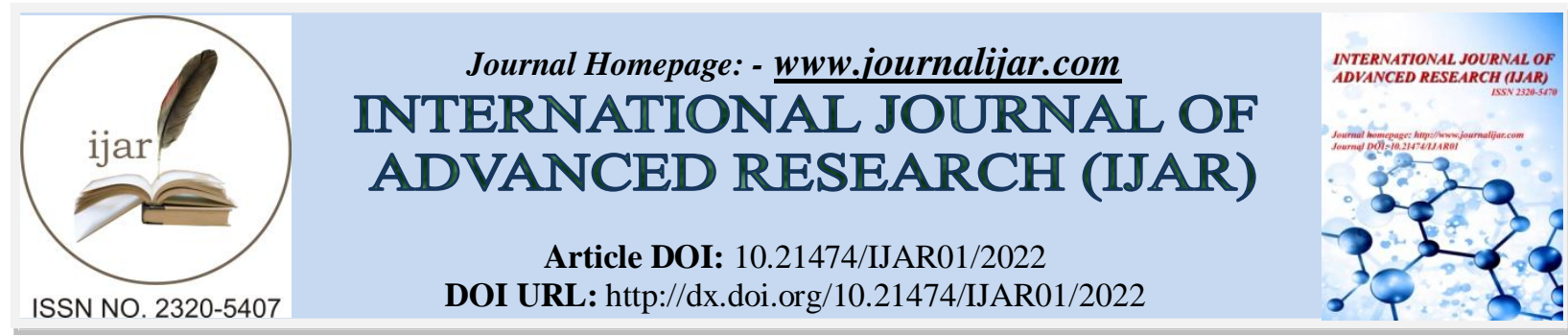

RESEARCH ARTICLE

\title{
PYLORIC DRAINAGE VERSUS NO DRAINAGE IN ESOPHAGOGATROSTOMIES AND EVALUATION OF INTRAOPERATIVE BALLOON DILATATION OF PYLORUS: A RANDOMISED CONTROLLED TRIAL.
}

\author{
Mir Fahiem-ul Hassan, Sajad Ahmad Wani, Mubashir A Shah. Hillal Ahmad Bhat, Abdul Majeed Dar \\ and Sameer Hassan Naqash
}

\section{Manuscript Info}

Manuscript History

Received: 25 September2016

Final Accepted: 9 October 2016

Published: October 2016

Key words:-

Esophagogatrostomies, Pyloric drainage procedures, intraoperative balloon dilatation, bile reflux esophagitis, dumping, delayed gastric emptying

\section{Abstract}

Background:-. Pyloric drainage procedures are supposed to prevent postoperative delayed gastric emptying but at the same time they may predispose to bile reflux esophagitis and dumping. We undertook this study to make a comparison of pyloric drainage procedures (viz: Heineke-Mikuliczpyloroplasty or intraoperative balloon dilatation of pylorus) with no pyloric drainage procedure, in patients undergoing resection for gastroesophageal junction, gastric cardia and proximal stomach cancers.

Methods:- Patients were randomly allocated to surgical procedures vizesophagogastrectomy without a drainage procedure $(n=35)$, esophagogastrectomy with pyloroplasty $(n=34)$ and esophagogastrectomy with intraoperative balloon dilatation of pylorus $(\mathrm{n}=35)$. Six months postoperatively patients were subjected to $\mathrm{Tc}^{99}$ gastric emptying scan to evaluate gastric emptying. At 8 months after surgery endoscopy was performed to look for bile reflux esophagitis.

Results:- Gastric emptying was delayed in $59.3 \%$ of our patients without significant difference among the groups studied. Bile reflux esophagitis was significantly high in pyloroplasty (28.6\%) andintaoperaive balloon dilatataion groups (26.7\%) as compared to no drainage group (3.6\%). Dumping was not found in patients of no drainage group. However in intraoperative balloon dilatation and pyloroplasty groups $21.8 \%$ and $18.2 \%$ of the patients suffered from dumping respectively which was again significantly high. There was no statistically significant difference in anastomotic leak, pulmonary complications and postoperative hospital stay among the three groups. Conclusion:- Pyloric drainage procedures like HeinekeMikuliczpyloroplasty and intraoperative balloon dilatation do not significantly improve gastric emptying whileas they promote bile reflux esophagitis and dumping. Also that the intraoperative balloon dilatation has no added advantage over conventional pyloroplasty. 


\section{Introduction:-}

Surgical resection is the mainstay of treatment for tumours of the lower esophagus, gastroesophageal junction and proximal stomach. A complete resection of tumour and its entire lymphatic drainage offers the best hope for long term survival [1]. Resection of these tumoursentails concomitant vagotomies [2,3] expectedly resulting in gastroparesis and delayed gastric emptying. Delayed gastric emptying may lead to anastomotic leak and pulmonary complications like aspiration pneumonia [4].Gastric drainage procedures like pyloroplasty and pyloromyotomy are frequently used with the idea to obviate the delayed gastric emptying and decrease the morbidity arising due to bilateral truncalvagotomy. However, such procedures may be complicated by dumping and duodenal bile reflux impairing late postoperative functional outcome [5]. Besides there is no conclusive evidence about the usefulness of pyloric drainage procedures in improving the gastric emptying following bilateral truncalvagotomies [4].Thus there is an ongoing debate about performing gastric drainage procedures after esophagogastrostomies.

\section{Materials and Methods:-}

A total of 104 patients were studied over a period of three years. Only the patients with resectable disease were taken as subjects for the study. Patients with stage-IV and/or unresectable disease were excluded from the study. Patients with a history of gastric outlet obstruction and those who had undergone previous gastric or intestinal reconstruction procedures were not included in the study. Patients were randomly allocated to different surgical procedures vizesophagogastrectomy without a drainage procedure (Group I: $n=35$ ), esophagogastrectomy with pyloroplasty (Group II: $n=34$ ) and esophagogastrectomy with intraoperative balloon dilatation of pylorus (Group III: $\mathrm{n}=35$ ).

Esophagogastric anastomosis was carried out through abdominal approach. End to end hand-sewn esophago-gastric anastomosis was carried out by using 3-0 silk sutures. Anastomosis was carried out in single layer interrupted fashion. Intraoperative balloon dilatation of the pylorus was carried out by 18 French Foley's catheter inflated by normal saline. Foley's catheter was passed through the remaining distal stomach into the pylorus(Fig 1\& Fig 2). 8$10 \mathrm{ml}$ of normal saline was used for the balloon inflation to attain a diameter of $18-20 \mathrm{~mm}$. Inflated balloon was put in pylorus for 2 minutes and was moved to and fro in pyloric canal around 2-3 times before removal. Pyloroplasty in our patients was done by standard Heineke-Mikulicz technique.

Figure 1:- Foley's catheter passing through the stomach into the pylorus.

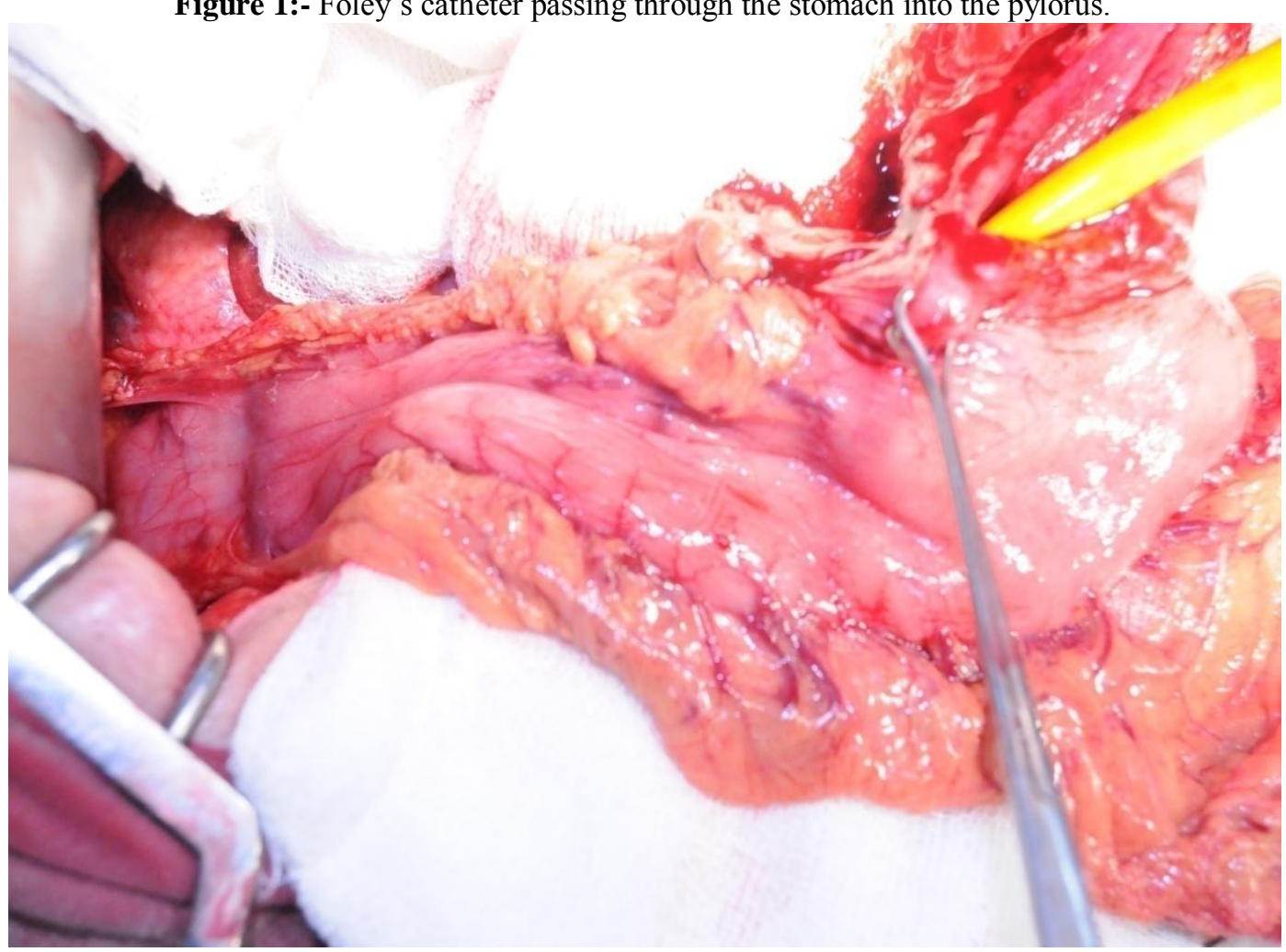


Figure 2:- Pylorus being stretched by inflated balloon of Foley's catheter.

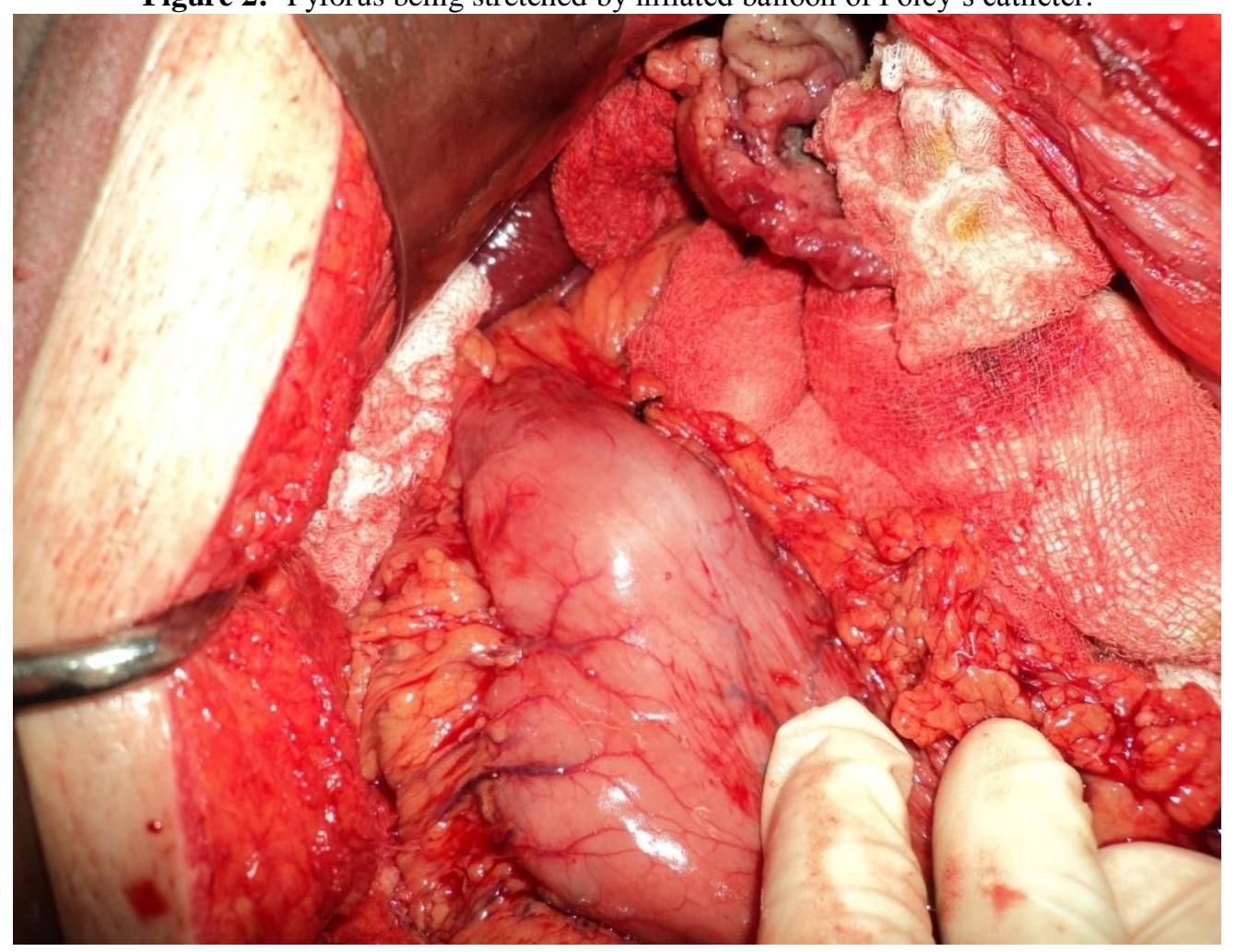

Six months postoperatively patients were subjected to $\mathrm{Tc}^{99}$ gastric emptying scan to evaluate gastric emptying. After overnight fasting, patients were advised to consume standard $\mathrm{Tc}^{99}$-labeled meal. The patients were asked to ingest the meal within 10 minutes of preparation. Gamma camera images were obtained immediately after meal ingestion and at time intervals of 1,2, and 4 hours after meal ingestion. The patients were asked to lie supine in front of a gamma camera. Delayed gastric empting was defined as per the guidelines of American Neuro-gastroenterology and Motility Society and the Society of Nuclear Medicine(2008). Gastric retention was determined as residual food in stomach: $>90 \%$ at 1 hour, $>60 \%$ at 2 hours, and $>10 \%$ at 4 hours.

At 8 months after surgery patients were subjected to endoscopy to look for bile reflux esophagitis as evidenced by bile in esophagus and confirmed by histopathology.

\section{Results:-}

Out of 104 patients enrolled for the study, 7 died in the early postoperative period and 11 patients were lost to follow up. Thus only 86 patients could be evaluated on follow up. There were 28 patients in no drainage group, 28 patients in pyloroplasty group and 30 patients in balloon dilatation group at the end of the study. Mean age of the patients studied was 61.67 7.1 years. Eighty six percent had adenocarcinoma and fourteen percent were diagnosed with squamous cell carcinoma.Gastric emptying was delayed in 59.3\% of our patients (Table 1). In no drainage group gastric emptying was delayed in $67.9 \%$ of patients whereas $57.1 \%$ patients in pyloroplasty group also had delayed gastric emptying.

Table 1:- Early and late post-operative complication.p1(No drainageVsPyloroplasty), p2 (No drainageVsBalloon dilatation), p3 (PyloroplastyVs Balloon dilatation).

\begin{tabular}{|l|l|l|l|l|}
\hline Complications & No drainage (\%) & Pyloroplasty (\%) & $\begin{array}{l}\text { Balloon dilatation } \\
(\mathbf{\%})\end{array}$ & Total(\%) \\
\hline Pneumonia & 8.6 & 2.9 & 8.6 & 6.7 \\
\hline Anastomotic leak & 8.6 & 5.8 & 5.7 & 6.7 \\
\hline $\begin{array}{l}\text { Symptomatic gastric } \\
\text { outlet obstruction }\end{array}$ & 9.3 & 9.1 & 18.7 & 12.4 \\
\hline Mean hospital stay & $22.83 \pm 8.67$ & $20.9 \pm 10.14$ & $21.33 \pm 9.82$ & $21.68 \pm 9.54$ \\
\hline
\end{tabular}


In intraoperative balloon dilatation group gastric emptying was delayed in $53 \%$ patients. However,this difference in gastric emptying times was not statistically significant. Bile reflux esophagitis was seen in 19.7\% of the patients. Pyloroplasty group had highest incidence of $28.6 \%$ followed by intraoperative balloon dilatation group (26.7\%). In no drainage group only $3.6 \%$ patients suffered from bile reflux esophagitis. The difference was statistically significant with more patients in pyloroplasty and intraoperative balloon dilatation groups suffering from bile reflux esophagitis. In our study, $13.4 \%$ patients had dumping. None of the patients in no drainage group had symptoms of dumping. However, in intraoperative balloon dilatation and pyloroplastygroups $21.8 \%$ and $18.2 \%$ of the patients suffered from dumping respectively which was significantly high as compared to no drainage group.

Features of gastric outlet obstruction postoperatively developed in $12.4 \%$ patients (Table 2). The incidence of gastric outlet obstruction was more in intraoperative balloon dilatation group with $18.7 \%$ patients in this group having signs and symptoms of gastric outlet obstruction.

Table 2:Summary of post-operative complications.p1, p2 \& p3>0.05

\begin{tabular}{|l|l|l|l|l|l|l|l|}
\hline Complications & $\begin{array}{l}\text { No drainage } \\
(\mathbf{\%})\end{array}$ & $\begin{array}{l}\text { Pyloroplasty } \\
(\mathbf{\%})\end{array}$ & $\begin{array}{l}\text { Balloon dilatation } \\
(\mathbf{\%})\end{array}$ & Total & P1 & P2 & P3 \\
\hline Delayed Emptying & 67.9 & 57.1 & 53 & 59.3 & $>0.05$ & $>0.05$ & $>0.05$ \\
\hline $\begin{array}{l}\text { Bile reflux } \\
\text { esophagitis }\end{array}$ & 3.6 & 28.6 & 26.7 & 19.7 & 0.025 & 0.02 & $>0.05$ \\
\hline Dumping & 0 & 18.2 & 21.8 & 13.4 & 0.02 & 0.01 & $>0.05$ \\
\hline
\end{tabular}

In no drainage group $9.3 \%$ patient had features of gastric outlet obstruction as compared to $9.1 \%$ patients in pyloroplasty group. Gastric outlet obstruction was unexpectedly high in balloon dilatation group probably due to the edema of pylorus following dilatation. It didn't seem to be much influenced by gastric emptying times as is evidenced by lower rates of obstruction in no drainage group (Fig 3).

Figure 3:- The gastric outlet obstruction didn't correlate with the delay in gastric emptying. It was found more often in patients of balloon dilatation.

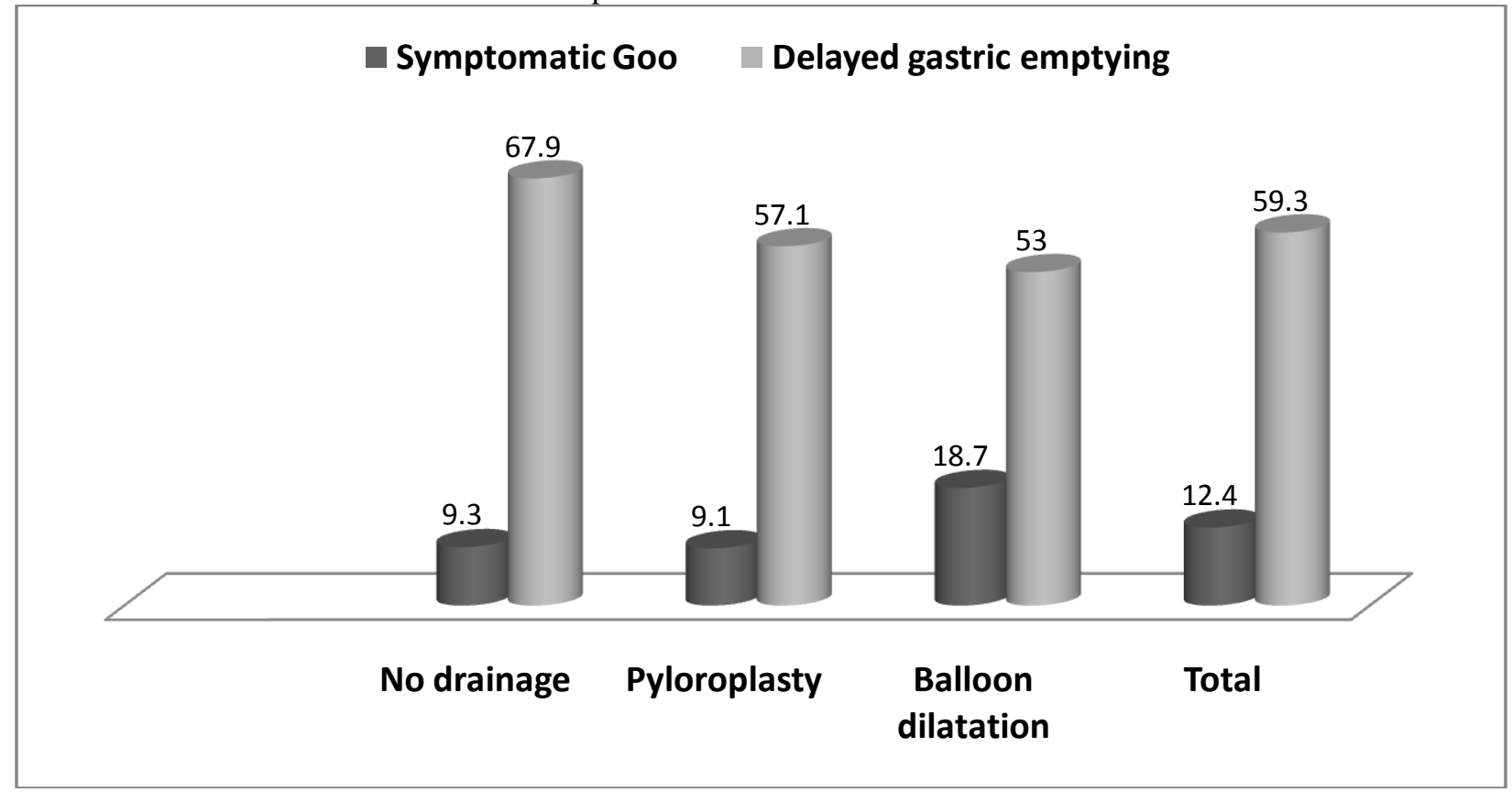

The incidence of pneumonia in our patients was 6.7\%.In no drainage group 8.6\%patients suffered from pneumonia postoperatively. $8.6 \%$ patients from intraoperative balloon dilatation group and $2.9 \%$ patient from pyloroplasty group also suffered from pneumonia postoperatively. Incidence of pneumonia was not statistically significant within the three groups. 
Anastomotic leak in our patients was seen in $6.7 \%$ patients. In no drainage group 3 patients $(8.6 \%)$ had anastomotic leak in comparison to 2 patients each in pyloroplasty (5.8\%) and intraoperative balloon dilatation groups (5.7\%). All these patients were managed conservatively and re-exploration was not needed. Even though on higher side in no drainage group anastomotic leak had no statistical significance within the groups studied.

\section{Discussion:-}

Esophagogastrostomies are invariably associated vagotomies [2,3] which are supposed to cause gastric stasis and delayed gastric emptying due to pyloric denervation [8,9]. To adressthis problem gastric drainage procedures like pyloroplasty and pyloromyotomy are routinely performed. Drainage procedures are used to improve gastric emptying [10,11,12,13] and hence reduce the risk of anastomotic leak and aspiration pneumonia [14]. However these procedures have been shown to be associated with complications like dumping and bile reflux esophagitis $[15,16]$.

In our study overall $59.3 \%$ patients had delayed gastric emptying on $\mathrm{Tc}^{99}$ scan. This delay in gastric emptying was not completely cured by drainage procedures undertaken which was obvious from the fact that $57.1 \%$ patients in pyloroplasty group and $53 \%$ patients in the balloon dilatation group still had delayed gastric emptying on Tc ${ }^{99}$ scan. $^{2}$ Besides majority of these patients were symptomless meaning thereby that the delayed gastric emptying doesn't necessarily cause symptomatic gastric oultlet obstruction in all patients (Fig:3) .

The features of gastric outlet obstruction were observed in only $9.3 \%$ patient in no drainage group compared to 9.1 $\%$ patients in pyloroplasty group and $18.7 \%$ patients in balloon dilatation group. Although, on higher side in intraoperative balloon dilatation group, gastric outlet obstruction, had no statistical significance within the three groups of the patients studied. It usually presented within a month after surgery. All the patients with gastric outlet obstruction were managed conservatively with nasogastric suction, replacement of fluids and electrolytes, proton pump inhibitors and prokinetics. However, no surgical or endoscopic intervention was required. There are studies which have found that the gastric outlet obstruction is of rare occurrence following esophagogastrostomies [17], as over a period of time denervated stomach regains its motor activity [18]. Even if gastric outlet obstruction occurs it can be managed conservatively with prokinetics [19,20]. Although very less in number but those patients who don't respond to conservative management can postoperatively undergo successful endoscopic balloon dilatation [17] of pylorus. In our study bile reflux esophagitis was significantly high in patients of pyloroplasty and intraoperative balloon dilatation groups as compared to no drainage group. Pyloroplasty group had highest incidence (28.6\%) followed by intraoperative balloon dilatation group (26.7\%). In no drainage group only $3.6 \%$ patients suffered from bile reflux esophagitis. In a study by Palmeset al [20] more patients with pyloric drainage showed bile reflux esophagitis (No drainage $=10.3 \%$ vs Pyloric drainage $=34.5 \%, p<0.05$ ). Gutschowetet al [16] reported 57\% of bile reflux in their patients with pyloric drainage. In a patient group of 52 that Bemelmanet al [15] studied, 42 had partial esophagogastrectomy and intrathoracicesophagogastrostomy, 12 with and 30 without a drainage procedure. Gastric stasis was not observed in the 12 patients with a drainage procedure, but in six duodenal reflux gastroesophagitis caused considerable morbidity. This complication was seen only once in the group $(n=38)$ who did not have a drainage procedure.

None of the patients in no drainage group had symptoms of dumping. However, in intraoperative balloon dilatation and pyloroplastygroups $21.8 \%$ and $18.2 \%$ of the patients suffered from dumping respectively. Dumping was significantly high in pyloroplasty and intraoperative balloon dilatation groupsas compared to no drainage group. More patients with pyloric drainage suffered from dumping. Studies by Humphrey et al [22] and Eckhauser et al [23] showed that about $10 \%$ to $30 \%$ of patients undergoing a vagotomy with pyloroplasty develop dumping syndrome with $1 \%$ to $5 \%$ refractory to conservative management. In 58 patients of no pyloric drainage Velanovich [24] reported no incidence of dumping syndrome.

In coherence with the other studies [25,26] we could not demonstrate a significant variation in the incidence of pneumonia, anastomotic leak and hospital stay in the three groups of the patients studied. We couldn't also find an additional benefit of using intraoperative balloon dilatation over traditional pyloroplasty. There was although a higher incidence of symptomatic gastric outlet obstruction in patients of intraoperative balloon dialation group as compared to pyloroplasty but this difference was not statistically significant. In concordance to our findings Manjariet al [27] was unable to demonstrate significant differences in the rate of gastric emptying at 6 weeks postesophagectomy when comparing pyloplasty, pyloromyotomy and pylorus stretching. 


\section{Conclusions:-}

Gastric drainage procedures like pyloroplasty or intraoperative balloon dilatation may be omitted while performing esophagogastrostomies with bilateral vagotomy as they do not completely cure delayed gastric emptying whereas they significantly predispose to bile reflux esophagitis and dumping. We also conclude that intraoperative balloon dilatation has no added advantage over conventional pyloroplasty.

\section{References:-}

1. J.R. Siewert, H.J. Stein, A. Sendler, U.Finku, Surgical resection of cancer of cardia, Seminars in Surgical Oncology. 17(1999) 125-131.

2. J.B.Jr.Putnam, J.A. Roth, Neoplasms of the esophagus, In: R.H. Bell, L.F.Rikkers, M.W. Mulholland, (Eds). Digestive Tract Surgery: a Text and Atlas, Philadelphia; Lippincott-Raven Publishers. (1996) 43-75.

3. S.J.Mulvihill, Neoplasms of the stomach,In: R.H. Bell, L.F. Rikkers, M.W. Mulholland, (Eds). Digestive Tract Surgery: a Text and Atlas, Philadelphia; Lippincott-Raven Publishers. (1996) 255-79.

4. T.Lerut, W.Coosemans, P.DeLeyn, D.VanRaemdonck,Gastroplasty : yes or no to gastric drainage procedure, Diseases of The Esophagus. 14(2001) 173-177.

5. L.S. Wang, M.H. Huang, B.S. Huang, K.Y.Chien, Gastric substitution for resectable carcinoma, an analysis of 368 cases, Annals of Thoracic Surgery. 53(1992) 289-94.

6. T.L. Abell, M.Camilleri, K.Donohoe, W.L.Hasler, H.C. Lin, A.H. Maurer, R.W. McCallum, T. Nowak, M.L.Nusynowitz, H.P. Parkman, P. Shreve, L.A.Szarka, W.J.Snape,H.A. Ziessman, Consensus recommendations for gastric emptying scintigraphy: A joint report of the American neurogastroenterology and motility society and the society of nuclear medicine, Journal of Nuclear Medicine and Technology. 36(2008) 44-54.

7. D. Moher, S. Hopewell, K.F. Schulz, V. Montori, P.C. Gøtzsche, P.J. Devereaux, D. Elbourne, M. Egger, D.G. Altman, CONSORT. CONSORT 2010 explanation and elaboration: updated guidelines for reporting parallel group randomised trials. International Journal of Surgery. 10 (2012) 28-55.

8. A.M. Dermond,Radical surgery in treatment of carcinoma of stomach, Proceedings of Royal Society of Medicine.69 (1976) 867.

9. H. Ellis, Surgical progress, Postgraduate Medical Journal. 52 (1976) 113.

10. M.Fok, S.W.K. Cheng, J. Wong,Pyloroplasty versus no drainage in gastric replacement of the esophagus, American Journal of Surgery. 162 (1991) 447-452.

11. H.C. Cheung, K.F.Siu, J. Wong, Is pyloroplasty necessary in esophageal replacement by stomach? A prospective, randomized controlled trial, Surgery 102(1987) 19-24.

12. Y. Nakane, T.Michiura, K. Inoue, M. Sato, K.Nakai, M.Ioka, K. Yamamichi, Role of pyloroplasty after proximal gastrectomy for cancer,Hepatogastroenterology. 51(2004) 1867-1871.

13. Y.Q. Wang,W.W. Ye, T. Lu, W.M. Zhang, Y. Xu. Application of mechanical dilatation of the pyloric sphincter in esophagectomy for esophageal carcinoma, Asian Cardiovascular Thoracic Annals.51 (2004) 12: 19-22.

14. . Mannell, A. McKnight, J.D. Esser, Role of pyloroplasty in the retrosternal stomach: results of a prospective, randomized controlled trial, British Journal of Surgery. 77 (1990) 57-59.

15. W.A.Bemelman, W.H.Brummelkamp, J.FBartelsman, Endoscopic balloon dilatation of the pylorus after esophagogastrostomy without a drainage procedure, Surgery, Gynecology \& Obstetrics. 170(1990) 424-426.

16. C.A.Gutschow, J.M. Collard, R. Romagnoli, J.M. Michel, M.Salizzoni, A.H. Holscher, Bile exposure of the denervated stomach as an esophageal substitute, Annals of Thoracic Surgery. 71 (2001) 1786-1791.

17. J.H. Kim, H.S. Lee, M.S. Kim, J.M. Lee, S.K.Kimb, J.I. Zo, Balloon dilatation of the pylorus for delayed gastric emptying after esophagectomy, European Journal of Cardio-thoracic Surgery. 33(2008) 1105-1111.

18. J.M. Collard, R.Romagnoli, J.B,Otte, P.J.Kestens, The denervated stomach as an esophageal substitute is a contractile organ, Annals of Surgery. 227(1998) 33-39.

19. J. Johansson, M. Sloth, M.Bajc, B. Walther, Radioisotope evaluation of the esophageal remnant and the gastric conduit after gastric pull-up esophagectomy, Surgery. 125(1999) 297-303.

20. T.N. Walsh, M.T Caldwell, C. Fallon, G. McGeown, D. Kidney, P. Freyne, P.J. Byrne, T.P. Hennessy, Gastric motility following oesophagectomy, British Journal Surgery.82 (1995) 91-4.

21. D. Palmes, M.Wellinghoff, M. Colombo-Benkman, N. Senninger, M.Bruewer, Effect of pyloric drainage procedures on gastric passage and bile reflux after esophagectomy with gastric conduit reconstruction,Langenbecks Archives of Surgery.392 (2007) 135-141. 
22. C.S. Humphrey, D. Johnston, B.E. Walker, C.N.Pulvertaft, J.C.Goligher, Incidence of dumping after truncal and selective vagotomy with pyloroplasty and highly selective vagotomy without drainage procedure, British Medical Journal. 3 (1972) 785-788.

23. F.E. Eckhauser, L.M.Colletti, W.L.Hasler, Postgastrectomy syndromes and motility disorders. In: R.H. Bell, L.F. Rikkers, M.W. Mulholland (Eds), Digestive Tract Surgery: a Text and Atlas. Philadelphia: LippincottRaven Publishers.(1996) 201-222.

24. V. Velanovich, Esophagogastrectomy without pyloroplasty, Diseases of Oesophagus, 16(2003) 243-245.

25. J.D. Urschel, C.J.Blewett, J.E. Young, J.D. Miller, W.F. Bennett,Pyloric drainage (pyloroplasty) or no drainage in gastric reconstruction after esophagectomy: a meta-analysis of randomized controlled trials, Digestive Surgery.3 (2002) 160-164.

26. G. Godazandeh, A.Khalilian, I. Maleki, H.Fakheri, F.Mahboob, H.Khani, S. Afzali,Randomised clinical trials of the effects of pyloromyotomy on transposed gastric emptying rate in patients with esophageal cancer after esophagectomy and cervical esophagogastrostomy. Surgery Journal.3 (2008) 6-12.

27. R. Manjari, A.K.Padhy, T.K.Chattopadhyay, Emptying of the intrathoracic stomach using three different pylorus drainage procedures--results of a comparative study, Surgery Today 26 (1996)581-585. 